International Journal of Applied Linguistics \& English Literature

ISSN 2200-3592 (Print), ISSN 2200-3452 (Online)

Vol. 1 No. 4; September 2012

\title{
A Study on the Relationship between Iranian EFL Learners' Beliefs and Their Writing Ability
}

\author{
Javad Javadi (corresponding author) \\ Department of English Language, Faculty of Foreign Languages, Islamic Azad University \\ Tonekabon Branch, Iran \\ Tel: +98-912-511-1941_Ｅ-mail: education_jj@yahoo.com \\ Dr. Shahrokh Jahandar \\ Department of English Language, Faculty of Foreign Languages, Islamic Azad University \\ Tonekabon Branch, Iran \\ Tel: $+98-9113940367$ \\ E-mail: shahrokhjahandar@gmail.com \\ Dr. Morteza Khodabandehlou \\ Department of English Language, Faculty of Foreign Languages, Islamic Azad University \\ Tonekabon Branch, Iran \\ Tel: +98-9113942038
}

Received: 11-06- 2012

Accepted: 23-07- 2012

Published: 01-09- 2012

doi:10.7575/ijalel.v.1n.4p.161

URL: http://dx.doi.org/10.7575/ijalel.v.1n.4p.161

\begin{abstract}
The current study aims to explore the relationship between Iranian EFL learners' beliefs about foreign language learning and their writing ability. An additional aim is to discover whether there is a significant effect of gender differences' learning beliefs on their writing ability. For making sure the Oxford Placement Test (OPT) was administered. A total of 80 students were homogeneously selected based on the OPT score among upper-intermediate participants in some English language institutes in Amol, Babol, and Babolsar, Mazandaran, Iran. The participants were asked to complete Horwitz's BALLI questionnaire (1987) to sort them out in control group (negative beliefs) and experimental group (positive beliefs). A post writing ability test (a free composition) was administered at the end of the semester. The given statements and scores were analyzed by Statistical Package for Social Sciences (SPSS) to assess the results. Furthermore Distribution of $\mathbf{t}$ was conducted for gender differences. The findings show a significant relationship between Iranian EFL learners' beliefs about foreign language learning and their writing ability. Participants who have more positive and realistic beliefs about foreign language learning made excellent to very good scores in their writing ability test and the students, who have negative and unrealistic beliefs about foreign language learning mostly made fair to poor in their writing ability test. The findings also reveal that there is no significant effect of gender differences' learning beliefs on their writing ability. There is no need for the teachers and students to be treated about the aims of the investigation.
\end{abstract}

Keywords: Learners' beliefs, Writing ability, Oxford placement test, The BALLI questionnaire

\section{Introduction}

\subsection{Overview}

In the last three decades, there has been a shift in focus in the field of second language acquisition from teaching methods to learner characteristics. It has become clearer that much of the responsibility for success in language learning may rest with the efforts of individual learners (Dehghan, 2011). Some of this change can be traced into learners' beliefs (Horwitz, 1987) and a group of techniques and strategies can be found in individual learners' efforts to learn a second or foreign language (Oxford, 1990). 
The present study is based on Horwitz's 1987 and1988 research indicating that learners' negative or positive beliefs about second or foreign language learning may affect the learners' achievement.

In the field of second language learning research, revealing information about the relationship between EFL learners' beliefs and their different skills of foreign language abilities does not have a long history. There is a growing body of evidence which suggests that beliefs play an important role in learning experience and achievements (Schommer, 1990).

Some beliefs are influenced by students' previous (positive or negative) experiences as language learners, while other beliefs are shaped by students' cultural background (Victori and Lockhart, 1995). Language learning is also different from other types of learning because probably no other field of study requires an individual to take social risks or endure potential public embarrassment in the way language study does (Horwitz, 1999). Horwitz (1987, 1988) indicates that students may lose their confidence when language classes fail to meet their expectations. So students' beliefs about foreign language learning have a crucial influence on their achievement. She also claims that foreign language teachers need to investigate learner beliefs about language learning.

\subsection{Theoretical Framework}

\section{- Learning Beliefs}

McDonough (1995) indicates that: "What we believe we are doing, what we pay attention to, what we think is important, how we choose to behave, how we prefer to solve problem, from the basis for our personal decisions as to how to proceed. An important fact about this argument is that it is not necessary for these kinds of evidence to be true for them to have important consequences for our further development" McDonough (1995, p.9).

Learners' beliefs, according to Richardson (1996) are "psychologically held understandings, premises, or propositions about the world that are felt to be true" (p.101). Learning a foreign language is different in many ways from learning other school subjects. Foreign language learning is almost certainly the subject of many firm beliefs and convictions among EFL learners all around the world. Beliefs may be derived from other sources like established practices, students' personality factors, educational principles, research-based evidence, and principles derived from an approach or method. It seems beliefs about language learning have been found to have a significant impact on the language learners, and also beliefs are guiding principles for the EFL learners as well (Cited in Dehghan, 2011).

\section{- Beliefs About Language Learning Inventory (BALLI)}

Horvitz (1987) offered Beliefs About Language Learning Inventory (BALLI) as a quantitative self-report questionnaire that investigates 34 different learner beliefs. BALLI includes five major areas:

a) Difficulty of language learning

b) Foreign language aptitude

c) The nature of language learning

d) Learning and communication strategies

e) Motivations and expectation

- Writing Ability

Nunan (2001) indicates, "Writing is usually thought to be the most difficult skill to acquire and should only be taught after students have learned the other skills. In terms of skills, producing a coherent, fluent, extended piece of writing is probably the most difficult thing there is to do in language" (p.271). He also indicates that writing is a very complex process in which a great number of cognitive and meta-cognitive activities take place. In terms of skills, producing a coherent, fluent, extended piece of writing is probably the most difficult thing there is to do in language. It is something most native speakers never master (Nunan, 2001).

At the present study, the researcher first tries to explore the Iranian EFL learners' beliefs about foreign language learning and then to explain how their learning beliefs relate to their writing ability. An additional aim of the current study is to discover whether there is a significant effect of gender differences' learning beliefs on their writing ability.

\section{- Appropriate Scales for Scoring}

The best way to test students' writing ability is to get them to write (Hughes, 2003). He also assumes that "the writing of elementary students is not to be tested. In testing writing we do not want to test anything other than the 
ability to write. In language testing we are not normally interested in knowing whether students are creative, imaginative, or even intelligent, have wide general knowledge, or have good reasons for the opinions they happen to hold. Therefore, for the sake of validity, we should not set tasks which measure theses abilities." (Hughes, 2003 p. 90). In evaluating student writing, the scoring may be analytical (i.e., based on specific aspect of writing ability) or holistic (i.e., based on a global interpretation of the effectiveness of that piece of writing). Depending on the purpose of evaluation, a numerical score or grade may be assigned.

\subsection{Statement of the Problem}

For most of the learners and teachers, the importance of the relationship between EFL learners' beliefs and their different skills of foreign language abilities is not revealed. And also they are not aware of the fact that beliefs play an important role in learning experience and achievements.

This is not our aim to cover the importance of writing in English language for the EFL students, or the shortage, limitations or difficulties of teaching or learning writing ability. This is not trivial but irrelevant to our study. It seems beliefs about language learning have a significant impact on the language learners.

Unfortunately little research has been conducted on the interaction of beliefs with other learning factors such as writing ability to better understand how these beliefs impact the writing skill of learning a foreign language. On the other hand as language educators have recognized that language learners bring to the classroom a complex set of attitudes, expectations, experiences, and beliefs, researches have begun to investigate learners' beliefs about the nature of language learning in an attempt to account for individual differences, and potential learning and teaching implications (Bernat and Gvozdenko 2005).

Is there any relationship between learners' beliefs about language learning and writing ability? So the present study aims to explore the relationship between the EFL learners' beliefs and their writing ability. To do so first the researcher tries to explore the Iranian EFL learners' beliefs about foreign language learning and then to explain how their learning beliefs relate to their writing ability. An additional aim of the current study is to discover whether there is a significant effect of gender differences' learning beliefs on their writing ability.

\subsection{Significance of the Study}

Although to date, there have been several studies to explore the relationship between EFL learners' beliefs and their strategy use; no researches have been studying the correlation between EFL learners' beliefs and their writing ability. The current study opens a new field to investigate. It analyzes Iranian EFL learners' beliefs.

The significance of this study is that identification of this relationship can suggest teachers to foster positive and realistic beliefs that lead to effective learning of writing ability and minimize negative and unrealistic beliefs that inhibit learning. Furthermore the present study can be beneficial to teachers, instructors, researchers, in Iranian contexts.

\subsection{Research Questions of the Study}

The following two research questions are addressed in the present research:

1. How specifically are foreign language learners' beliefs about language learning related to their writing ability?

2. Is there any significant effect of gender differences' learning beliefs on their writing ability?

The following hypotheses are drawn:

1. There is relationship between Iranian EFL learners' beliefs and their writing ability.

2. There is not significant effect of gender differences' Learning beliefs on their writing ability.

\section{Literature Review}

\subsection{Researches in Iran into beliefs about language learning}

Dehghan Harati (2011) conducted an investigation on the 30 undergraduate EFL learners' beliefs toward FLL and that of their teachers at Sheikhbahaee University to see whether there is any gap between the beliefs of the teachers and students or not. In his study, 30 linguistically homogenous female students (based on OPT scoresintermediate group) and ten of their teachers were selected and asked to complete the Persian version of Horwitz' BALLI. The findings revealed that learners had different beliefs toward learning English as a foreign language. The mismatch between learners' and teachers' beliefs was more apparent in greater emphasis of students on the role of grammar, vocabulary, pronunciation and translation indicating the fact that their beliefs are more in line 
with traditional approaches to language learning. They also tended to underestimate the length of time it takes to become fluent in L2. Moreover, Students and teachers had different beliefs as far as the influence of one's gender and intelligence on foreign language acquisition processes is concerned (Dehghan Harati, 2011).

Zare-ee (2010), his study aimed at describing Iranian University EFL learners' beliefs about language learning and exploring how such beliefs might affect the deployment of different cognitive, meta-cognitive, social, and affective language learning strategies.

His descriptive and inferential data analyses indicated that beliefs about language learning were significantly related to language learning strategy use and language proficiency (Zare-ee (2010).

Ghobadi and Khodadady (2001), their study aimed to investigate beliefs students usually held about language learning, based on the Beliefs About Language Learning Inventory (BALLI) questionnaire (Horwitz, 1988). For this purpose, 423 University learners of English in Iran were selected. The findings of the their study suggest that teachers should be aware of learners' beliefs of language learning as well as their own in order to assist less successful language learners to become successful.

\section{Methodology}

\subsection{Participants}

Although the curriculum of upper-intermediate level in Iranian English Institutes is approximately the same, but for making sure the Oxford Placement Test (OPT) had been administered. A total of 80 students (50 females and 30 males) were homogeneously selected based on the OPT score among upper-intermediate participants in some English language institutes in Amol, Babol, and Babolsar, Mazandaran, Iran. All students fall into the 18-24 age range. The number of female students is naturally more than the males in Iranian contexts. The participants were asked to complete Horwitz's BALLI questionnaire (1987) to sort them out in control group (negative beliefs) and experimental group (positive beliefs). The BALLI is a quantitative self-report questionnaire that investigates 34 different learner beliefs on a likert-scale. A post writing ability test (a free composition) was administered at the end of the semester. Participants who have more positive and realistic beliefs about foreign language learning make good to excellent scores in their writing ability test and the students, who have negative and unrealistic beliefs about foreign language learning mostly make fair to poor in their writing ability test. The given statements and scores were analyzed by Statistical Package for Social Sciences (SPSS) to assess the results. Furthermore Distribution of $\mathbf{t}$ was conducted for gender differences.

\subsection{Materials (Instruments)}

In our study, two types of instruments were used in order to collect data:

\section{a. The Oxford Placement Test (OPT)}

The Oxford Placement Test measures a test takers' ability to communicate in English. It gives the instructors the information they need to find out about a person's language level. Usually before enrolling in one of the English language courses, they have to take a level test which will help the teachers identify the learners' level of English. The Oxford Placement Test was administered at the beginning of the study to find the exact upper-intermediate level of the students.

b. Beliefs About Language Learning Inventory (BALLI)

Horvitz, (1987) offered BALLI as a quantitative self-report questionnaire that investigates 34 different learner beliefs. BALLI includes five major areas:

A) Motivations and expectation: items 5, 20, 24, 29, 31, and 32.

B) The nature of language learning: items 8, 12, 17, 23, 27, 28 .

C) Learning and communication strategies: items 7, 9, 13, 14, 18, 21, 22, and 26.

D) Foreign language aptitude: items: 1, 2, 6, 10, 11, 16, 19, 30, and 33.

E) Difficulty of language learning: items 3, 4, 15,25and 34 .

The survey instrument asks participants to rate their agreement to 34 statements on a Likert-scale. This instrument is scored on a five-point Likert scale, ranging from "1: strongly disagree" to " 5 : strongly agree". The questions are in English language. BALLI is a kind of standard questionnaire with a Cronbach alpha of 0.79. Acceptable value of Cronbach alpha is at least 0.70 . Subjects are asked to read the statements and decide if they (1) strongly disagree,(2) disagree, (3) neither agree nor disagree, (4) agree, or (5) strongly agree with each statement. 


\subsection{Data Analysis Procedures}

Quantitative and qualitative data analyses were performed in this study. The quantitative analysis involved several statistical procedures: descriptive statistics, including frequencies, means, and standard deviations, were computed to summarize the students' responses to their beliefs. The qualitative data analysis refers to the composition score of the students. The given scores and statements were analyzed by Statistical Package for Social Sciences (SPSS) and Distribution of $t$ was conducted for gender differences. There is no need for the teachers and students to be treated during the investigation.

Participants who have more positive and realistic beliefs about foreign language learning make good to excellent scores in their writing ability test and the students, who have negative and unrealistic beliefs about foreign language learning mostly make fair to poor in their writing ability test. To gain a higher score of reliability the composition of the 80 students were corrected by four teachers. Two teachers corrected the composition holistically, while the other two teachers corrected the compositions analytically. And the means of the scores are the final scores of the students.

The data collection procedure was started at the beginning of the summer semester in July 2011 - August 2011. In the initial phase, the students were asked to take the Quick Oxford Placement Test version1 to select the exact upper-intermediate level of the students among the120 female and male students in some English language institutes at the level of upper-intermediate.

\section{Results}

4.1 Data Analysis and Finding on the Motivation and Expectations

Table 1. Response frequency for the motivation and expectations

\begin{tabular}{ccccccccccccccccc}
\hline Items & \multicolumn{1}{c}{ Males } & \multicolumn{1}{c}{ Females } & \multicolumn{1}{c}{ Total } \\
\hline & $\mathrm{a}$ & $\mathrm{B}$ & $\mathrm{c}$ & $\mathrm{d}$ & $\mathrm{E}$ & $\mathrm{a}$ & $\mathrm{b}$ & $\mathrm{C}$ & $\mathrm{D}$ & $\mathrm{e}$ & $\mathrm{a}$ & $\mathrm{b}$ & $\mathrm{c}$ & $\mathrm{d}$ & $\mathrm{E}$ \\
5 & 0 & 1 & 10 & 6 & 13 & 1 & 6 & 9 & 16 & 18 & 1 & 7 & 19 & 22 & 31 \\
20 & 2 & 8 & 3 & 16 & 1 & 0 & 8 & 8 & 28 & 6 & 2 & 16 & 11 & 44 & 7 \\
24 & 0 & 5 & 7 & 13 & 5 & 2 & 17 & 10 & 18 & 3 & 2 & 22 & 17 & 31 & 8 \\
29 & 0 & 1 & 4 & 13 & 12 & 1 & 10 & 7 & 21 & 11 & 1 & 11 & 11 & 34 & 23 \\
31 & 0 & 0 & 2 & 14 & 14 & 1 & 6 & 6 & 17 & 20 & 1 & 6 & 8 & 31 & 34 \\
32 & 0 & 4 & 2 & 15 & 9 & 2 & 6 & 9 & 23 & 10 & 2 & 10 & 11 & 38 & 19 \\
\hline
\end{tabular}

Note1: The percentage has been rounded off to the nearest hundredth.

Note2: Number of males $=30$ number of females $=50 \quad$ total $=80$

Note 3 : $\mathrm{a}=$ strongly disagree, $\mathrm{b}=$ disagree, $\mathrm{c}=$ neither agree nor disagree, $\mathrm{d}=$ agree, $\mathrm{e}=$ strongly agree

Statement5 = I believe that I will ultimately learn to speak English very well.

Statement20 $=$ People in my country feel that it is important to speak English.

Statement24 = I would like to learn English so that I can get to know native speakers of English better.

Statement29 = If I learn English very well, I will have better opportunities for a good job.

Statement31 = I want to learn to speak English well.

Statement32 = I would like to have native-English speaking friends.

Statement14 = It's OK to guess if you don't know a word in English.

Statement18 = It is important to repeat and practice a lot.

Statement21 = I feel timid (shy) speaking English with other people.

Statement22 = If beginning students are permitted to make errors in English, it will be difficult for them to speak correctly later on.

Statement26 = It is important to practice with audio materials.(The red lines should be omitted.)

BALLI items 5, 20, 24, 29, 31, and 32 concern the motivation of the students associate with the learning of the foreign language. 
For item 5, "I believe that I will ultimately learn to speak English very well." (66\%) of the participants reported that they expected to ultimately learn English very well (63\% males, $68 \%$ females). However, (totally $24 \%, 33 \%$ males and $18 \%$ females) of respondents neither agreed nor disagreed that they ultimately learn to speak English very well. For item 20, "People in my country feel that it is important to speak English", (64\%) of the total respondents strongly agreed or agreed with this notion (57\% males and $68 \%$ females). While $(33 \%)$ of male and $(18 \%)$ of female respondent had a neutral idea about this notion.

For item 24, "I would like to learn English so that I can get to know native speakers of English better", (60\%) of male while only ( $42 \%)$ of female respondents expressed the desire to like to learn English so that they can get to know native speakers of English better. So totally (49\%) of respondents had a positive idea about this item. However, (10\% totally, $07 \%$ males and $12 \%$ females) of respondents were neither agreed nor disagreed with this idea. For item 29, "If I learn English very well, I will have better opportunities for a good job", it is not surprising that the respondents perceived that English would give them better opportunities for a good job. In fact, (71\%) of respondents are either strongly agreed or agreed with this notion ( $83 \%$ males and $64 \%$ females). However, (14\% totally, $13 \%$ males and $14 \%$ females) of respondents were neither agreed nor disagreed with this idea. For item 31 , "I want to learn to speak English well", most of the participants in each group expressed their wish to learn English well", (93\%) of male respondents stated that they wanted to learn to speak English well, while (74\%) of female respondents their positive idea. So totally $(81 \%)$ of respondents stated their positive statement. However, $(21 \%$ totally, 23\% males and 20\% females) of respondents were neither agreed nor disagreed with this idea.

For item 32, "I would like to have native-English speaking friends", (71\%) of the learners expressed their positive ideas about having native-English speaking friends ( $80 \%$ males, ( $66 \%$ females). $(7 \%)$ of male and $18 \%$ of female learners had a neutral idea about this notion.

\subsection{Data Analysis and Finding on the Nature of Language Learning}

Table 2. Response frequency for the nature of the language learning

\begin{tabular}{ccccccccccccccccc}
\hline Items & \multicolumn{1}{c}{ Males } & \multicolumn{1}{c}{ Females } & \multicolumn{1}{c}{ total } \\
\hline & $\mathrm{a}$ & $\mathrm{B}$ & $\mathrm{c}$ & $\mathrm{d}$ & $\mathrm{e}$ & $\mathrm{a}$ & $\mathrm{b}$ & $\mathrm{C}$ & $\mathrm{D}$ & $\mathrm{e}$ & $\mathrm{a}$ & $\mathrm{b}$ & $\mathrm{c}$ & $\mathrm{d}$ & $\mathrm{e}$ \\
8 & 2 & 8 & 17 & 11 & 2 & 1 & 10 & 13 & 21 & 5 & 3 & 18 & 20 & 32 & 7 \\
12 & 0 & 2 & 7 & 9 & 12 & 2 & 7 & 6 & 20 & 15 & 2 & 9 & 13 & 29 & 27 \\
17 & 1 & 12 & 5 & 10 & 2 & 0 & 19 & 9 & 22 & 0 & 1 & 31 & 14 & 32 & 2 \\
23 & 3 & 22 & 3 & 2 & 0 & 3 & 34 & 8 & 5 & 0 & 6 & 56 & 11 & 7 & 0 \\
27 & 0 & 0 & 8 & 19 & 3 & 2 & 7 & 21 & 16 & 4 & 2 & 7 & 29 & 35 & 7 \\
28 & 2 & 15 & 6 & 6 & 1 & 3 & 29 & 7 & 9 & 2 & 5 & 44 & 13 & 15 & 3 \\
\hline
\end{tabular}

Note1: The percentage has been rounded off to the nearest hundredth.

Note2: Number of males $=30$ number of females $=50 \quad$ total $=80$

Note3: $\mathrm{a}=$ strongly disagree, $\mathrm{b}=$ disagree, $\mathrm{c}=$ neither agree nor disagree, $\mathrm{d}=$ agree, $\mathrm{e}=$ strongly agree

Statement8 $=$ It is necessary to know about English-speaking cultures in order to speak English.

Statement12 = It is best to learn English in an English-speaking country.

Statement $17=$ The most important part of learning a foreign language is learning vocabulary.

Statement23 = The most important part of learning a foreign language is learning the grammar.

Statement $27=$ Learning a foreign language is different from learning other academic subjects.

Statement28 $=$ The most important part of learning English is learning how to translate from my native language.

BALLI items $8,12,17,23,27$ and 28 include a range of issues related to the nature of the language learning process. Item 8 and 12 concern the role of cultural issues in language learning. Item 27 indicates that learning a foreign language is different from learning other academic subjects, while item 17, 23, and 28 concern the language learning task.

For item 8, "It is necessary to know about English-speaking cultures in order to speak English." (43\%) of male while (52\%) of female respondents expressed the desire to like to know English-speaking cultures in order to speak 
English. They concern the role of cultural contact in their learning. So totally (49\%) of respondents had a positive idea about this item. However, ( $25 \%$ totally, $57 \%$ males and $26 \%$ females) of respondents were neither agreed nor disagreed with this idea.

For item 12, "It is best to learn English in an English-speaking country." Surprisingly (70\%) of the total participants' thought that it is best to learn a foreign language in the foreign country, $(57 \%)$ of male and $(70 \%)$ of female respondents expressed the desire to learn English in an English-speaking country while (14\%) of the participants thought the opposite. However, (16\% totally, $23 \%$ males and $12 \%$ females) of respondents were neither agreed nor disagreed with this idea.

For item 17, "The most important part of learning a foreign language is learning vocabulary." (40\%) of male while $(44 \%)$ of female respondents expressed the idea about the importance of vocabulary in foreign language learning. They concern the role of vocabulary in their learning. So totally $(16 \%)$ of respondents had a positive idea about this item. However, (18\% totally, $18 \%$ males and $17 \%$ females) of respondents were neither agreed nor disagreed with this idea.

For item 23, "The most important part of learning a foreign language is learning the grammar" Only (7\%) of male and $(10 \%)$ of female respondents expressed the idea about the importance of grammar in foreign language learning. In fact participants didn't think that learning a foreign language is mostly a matter of learning a lot of grammar rules. So totally $(9 \%)$ of respondents agreed with this item. However, $(14 \%$ totally, $10 \%$ males and $16 \%$ females) of respondents were neither agreed nor disagreed with this idea.

For item 27, "Learning a foreign language is different from learning other academic subjects." (7\%) of male and $(40 \%)$ of female respondents agreed that learning a foreign language is different from learning other academic subjects. So totally $(56 \%)$ of respondents had a positive idea about this item. However, (36\% totally, $27 \%$ males and $42 \%$ females) of respondents were neither agreed nor disagreed with this idea.

For item 28, "The most important part of learning English is learning how to translate from my native language." almost most of the participants disagreed that the most important part of learning a foreign language is learning how to translate from English.

\subsection{Data Analysis and Finding on Learning and Communication Strategies}

Table 3. Response frequency for learning and communication strategies

\begin{tabular}{ccccccccccccccccc}
\hline Items & \multicolumn{1}{c}{ Males } & \multicolumn{1}{c}{ Females } & \multicolumn{1}{c}{ Total } \\
\hline & $\mathrm{a}$ & $\mathrm{B}$ & $\mathrm{c}$ & $\mathrm{d}$ & $\mathrm{e}$ & $\mathrm{a}$ & $\mathrm{b}$ & $\mathrm{C}$ & $\mathrm{D}$ & $\mathrm{e}$ & $\mathrm{a}$ & $\mathrm{b}$ & $\mathrm{c}$ & $\mathrm{d}$ & $\mathrm{E}$ \\
9 & 0 & 9 & 6 & 11 & 4 & 2 & 15 & 7 & 13 & 13 & 2 & 24 & 13 & 24 & 17 \\
13 & 8 & 17 & 4 & 1 & 0 & 19 & 27 & 2 & 2 & 0 & 27 & 44 & 6 & 3 & 0 \\
14 & 0 & 1 & 1 & 17 & 11 & 2 & 6 & 4 & 20 & 18 & 2 & 7 & 5 & 37 & 29 \\
18 & 0 & 2 & 6 & 17 & 5 & 0 & 2 & 3 & 35 & 10 & 0 & 4 & 9 & 52 & 15 \\
21 & 4 & 0 & 0 & 21 & 9 & 0 & 5 & 0 & 20 & 25 & 0 & 5 & 0 & 41 & 34 \\
22 & 2 & 23 & 4 & 1 & 1 & 13 & 19 & 10 & 7 & 1 & 17 & 31 & 22 & 8 & 2 \\
26 & 0 & 0 & 3 & 22 & 5 & 1 & 0 & 7 & 28 & 14 & 1 & 0 & 10 & 50 & 19
\end{tabular}

Note1: The percentage has been rounded off to the nearest hundredth.

Note2: Number of males $=30$ number of females $=50 \quad$ total $=80$

Note3: $\mathrm{a}=$ strongly disagree, $\mathrm{b}=$ disagree, $\mathrm{c}=$ neither agree nor disagree, $\mathrm{d}=$ agree, $\mathrm{e}=$ strongly agree

Statement $7=$ It is important to speak English with an excellent pronunciation.

Statement9 = You shouldn't speak anything in English until you can say it correctly.

Statement13 = I enjoy practicing English with the native speakers of English I meet.

Statement14 = It's OK to guess if you don't know a word in English

Statement $18=$ It is important to repeat and practice a lot

Statement21 = I feel timid (shy) speaking English with other people 
Statement22 = If beginning students are permitted to make errors in English, it will be difficult for them to speak correctly later on

Statement26 = It is important to practice with audio materials

BALLI items 7, 9, 13, 14, 18, 21, 22, and 26 address learning and communication strategies and are probably the most directly related to a student's actual language learning practices. Items 18 and 26 refer to learning strategies, and items 7, 9, 13, 14, 21 and 22 concern communication strategies. First, with reference to traditional learning strategies, students strongly endorsed repetition and practice with cassettes or tapes (audio materials). For statement13, "I enjoy practicing English with the native speakers of English I meet.

Actually (83\%) of respondents enjoyed practicing English with the native speakers of English they meet, and for item 18, "It is important to repeat and practice a lot." Almost all respondents (94\%) believed that it is important to repeat and practice a lot. For statement22, "If beginning students are permitted to make errors in English, it will be difficult for them to speak correctly later on." Only (10\%) of respondents either strongly agreed or agreed that if beginning students are allowed to make mistakes in English, it will be difficult for them to speak correctly later on. On the other hand, for item 9, "You shouldn't speak anything in English until you can say it correctly." (3\%) of male and $(4 \%)$ of female respondents agreed with the item. So totally $(4 \%)$ of respondents had a positive idea about this item.

Concerning the area of communication strategies, for item7, "It is important to speak English with an excellent pronunciation." they agreed on the importance of an excellent pronunciation (51\%). Exactly half of the participants disagreed that they shouldn't say anything in the English language until they can say it correctly and also for statement14, "it's OK to guess if you don't know a word in English." (73\%) of male and (90\%) of female respondents agreed that they try to guess the meaning of a word that they don't know the meaning. So totally $(84 \%)$ of respondents had a positive idea about this item. However, (11\% totally, $20 \%$ males and $6 \%$ females) of respondents were neither agreed nor disagreed with this idea. According to statement 26 , "it is important to practice with audio materials." $(86 \%)$ of respondents had a positive idea about this item. $(90 \%)$ of male and (84\%) of female respondents agreed that it is important to practice with audio materials.

Also among the participants, for the item 21, "I feel timid (shy) speaking English with other people." Most of the respondents stated that they feel self-conscious speaking the English language in front of other people.

4.4 Data Analysis and Finding on Foreign Language Aptitude

Table 4. Response frequency for foreign language aptitude

\begin{tabular}{cccccccccccccccc}
\hline Items & \multicolumn{1}{c}{ Males } & \multicolumn{1}{c}{ Females } & \multicolumn{7}{c}{ Total } \\
\hline & $\mathrm{a}$ & $\mathrm{B}$ & $\mathrm{c}$ & $\mathrm{d}$ & $\mathrm{e}$ & $\mathrm{a}$ & $\mathrm{b}$ & $\mathrm{C}$ & $\mathrm{D}$ & $\mathrm{e}$ & $\mathrm{a}$ & $\mathrm{b}$ & $\mathrm{c}$ & $\mathrm{d}$ & $\mathrm{E}$ \\
1 & 0 & 4 & 6 & 13 & 7 & 4 & 8 & 11 & 15 & 12 & 4 & 12 & 17 & 28 & 19 \\
2 & 0 & 8 & 2 & 14 & 6 & 0 & 21 & 7 & 12 & 10 & 0 & 29 & 9 & 26 & 16 \\
6 & 0 & 6 & 16 & 8 & 0 & 8 & 7 & 17 & 18 & 0 & 8 & 13 & 33 & 26 & 0 \\
10 & 0 & 7 & 12 & 10 & 1 & 3 & 6 & 19 & 18 & 4 & 3 & 13 & 31 & 28 & 5 \\
11 & 8 & 12 & 10 & 0 & 0 & 17 & 20 & 12 & 1 & 0 & 25 & 32 & 22 & 1 & 0 \\
16 & 0 & 7 & 7 & 11 & 5 & 0 & 7 & 16 & 18 & 9 & 0 & 14 & 23 & 29 & 14 \\
19 & 6 & 16 & 7 & 1 & 0 & 4 & 20 & 20 & 3 & 3 & 10 & 36 & 27 & 4 & 3 \\
30 & 0 & 5 & 14 & 11 & 0 & 3 & 11 & 18 & 13 & 5 & 3 & 16 & 32 & 24 & 5 \\
33 & 1 & 6 & 5 & 17 & 1 & 1 & 12 & 13 & 21 & 3 & 2 & 18 & 18 & 38 & 4 \\
\hline
\end{tabular}

Note1: The percentage has been rounded off to the nearest hundredth.

Note2: Number of males $=30$ number of females $=50 \quad$ total $=80$

Note 3 : $a=$ strongly disagree, $\mathrm{b}=$ disagree, $\mathrm{c}=$ neither agree nor disagree, $\mathrm{d}=$ agree, $\mathrm{e}=$ strongly agree

Statement1 $=$ It is easier for children than adults to learn a foreign language.

Statement $2=$ Some people have a special ability for learning a foreign language.

Statement6 $=$ People from my country are good at learning foreign languages.

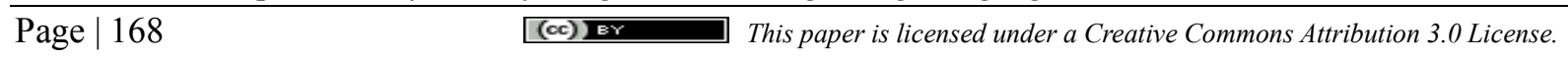


Statement10 = It is easier for someone who already speaks a foreign language to learn another one.

Statement1 1 = People who are good at mathematics or science are not good at learning foreign languages.

Statement16 $=$ I have a special ability for learning foreign languages.

Statement $19=$ Women are better than men at learning foreign languages.

Statement30 = People who speak more than one language are very intelligent.

Statement33 = Everyone can learn to speak a foreign language.

BALLI items 1, 2, 6, 10,11, $1619,30,33$ relate to the general existence of specialized abilities for language learning and beliefs about the characteristics of successful and unsuccessful language learners. Thus, these items address the issue of individual potential for achievement in language learning. In this study, the respondents generally endorsed the concept of special abilities for foreign/second language learning. Statement1, "It is easier for children than adults to learn a foreign language." most students agreed that it is easier for children than adults to learn a foreign language (59\%). However, (21\% totally, 20\% males and 22\% females) of respondents were neither agreed nor disagreed with this idea. (53\%) either strongly agreed or agreed with the statement2, "Some people have a special ability for learning foreign languages", and (54\%) strongly agreed and agreed with the Statement16, "I have a special ability for learning foreign languages." About statement6, "People from my country are good at learning foreign languages." (27\%) of male and (36\%) of female respondents agreed with the item. So totally (33\%) of respondents had a positive idea about this item. However, (41\% totally, 53\% males and 34\% females) of respondents were neither agreed nor disagreed with this idea.

About statement 10 "It is easier for children than adults to learn a foreign language". (37\%) of male and (44\%) of female respondents agreed with the item. So totally (41\%) of respondents had a positive idea about this item. However, (39\% totally, $40 \%$ males and 38\% females) of respondents were neither agreed nor disagreed with this idea. Statement11, "People who are good at mathematics or science are not good at learning foreign languages." They did not agree that people who are good at mathematics or science are not good at learning foreign languages. Only (1\%) of the respondents are agree with this statement. Statement19, "Women are better than men at learning foreign languages." they were mostly disagree about the idea of women being better than men at learning foreign languages. Surprisingly (12\%) of female respondents are agree with this statement while only (3\%) of male respondents express their agreement of the statement.

For statement30, "People who speak more than one language are very intelligent." (37\%) of male and (36\%) of female respondents agreed with the item. So totally (36\%) of respondents had a positive idea about this item. However, (40\% totally, $47 \%$ males and $36 \%$ females) of respondents were neither agreed nor disagreed with this idea. Statement33, "Everyone can learn to speak a foreign language." (53\%) of the participants of male and female agreed that anyone can learn a foreign language.

\subsection{Data Analysis and Finding on Difficulty of Learning a Foreign Language}

Table 5. Response frequency for the difficulty of language learning

\begin{tabular}{ccccccccccccccccc}
\hline Items & \multicolumn{1}{c}{ Males } & \multicolumn{1}{c}{ Females } & \multicolumn{1}{c}{ Total } \\
\hline & $\mathrm{a}$ & $\mathrm{B}$ & $\mathrm{c}$ & $\mathrm{d}$ & $\mathrm{e}$ & $\mathrm{a}$ & $\mathrm{b}$ & $\mathrm{C}$ & $\mathrm{D}$ & $\mathrm{e}$ & $\mathrm{a}$ & $\mathrm{b}$ & $\mathrm{c}$ & $\mathrm{d}$ & $\mathrm{E}$ \\
3 & 0 & 0 & 8 & 16 & 6 & 1 & 6 & 14 & 21 & 8 & 1 & 6 & 22 & 37 & 14 \\
4 & 0 & 1 & 24 & 5 & 0 & 1 & 4 & 33 & 11 & 1 & 1 & 5 & 57 & 16 & 1 \\
15 & 1 & 8 & 18 & 3 & 0 & 4 & 14 & 19 & 8 & 5 & 5 & 22 & 37 & 11 & 5 \\
25 & 5 & 10 & 8 & 5 & 2 & 10 & 22 & 9 & 8 & 1 & 15 & 32 & 17 & 13 & 3 \\
34 & 1 & 14 & 5 & 8 & 2 & 7 & 22 & 8 & 12 & 1 & 8 & 36 & 13 & 20 & 3 \\
\hline
\end{tabular}

Note1: The percentage has been rounded off to the nearest hundredth.

Note2: Number of males $=30$ number of females $=50 \quad$ total $=80$

Note3: $\mathrm{a}=$ strongly disagree, $\mathrm{b}=$ disagree, $\mathrm{c}=$ neither agree nor disagree, $\mathrm{d}=$ agree, $\mathrm{e}=$ strongly agree

Statement $3=$ Some languages are easier to learn than others. 
Statement 4 = English is: a) a very difficult language b) a difficult language c) a language of medium difficulty d) an easy language e) a very easy language.

Statement 15 = If someone spent one hour a day learning a language, how long would it take for them to speak the language very well?: a) less than a year b) 1-2 years c)3-5 years d) 5-10 years e) You can't learn a language in 1 hour a day.

Statement25 $=$ It is easier to speak than understand a foreign language.

Statement34 = It is easier to read and write English than to speak and understand it.

BALLI items $3,4,15,25$, and 34 concern the general difficulty of learning a foreign language and the specific difficulty of the students' particular target language. Items 34 assess the relative difficulty of different language skills.

According to statement3, "Some languages are easier to learn than others." (73\%) of male and $(58 \%)$ of female respondents agreed with the item. So totally (64\%) of respondents had a positive idea about this item. However, ( $28 \%$ totally, $27 \%$ males and $28 \%$ females) of respondents were neither agreed nor disagreed with this idea.

Regarding statement4, "English is: a) a very difficult language b) a difficult language c) a language of medium difficulty d) an easy language e) a very easy language." (17\%) of male and (24\%) of female respondents expressed that English is an easy language; it is not very difficult to learn. So totally $(21 \%)$ of respondents had an easy idea about learning English as a foreign language. However, (71\% totally, $80 \%$ males and $66 \%$ females) of respondents stated that English is a language of medium difficulty.

Statement15, "If someone spent one hour a day learning a language, how long would it take for them to speak the language very well?: a) less than a year b) 1-2 years c)3-5 years d) 5-10 years e) You can't learn a language in 1 hour a day." (10\%) of male and (26\%) of female respondents selected (d) and (e) items. However, (46\% totally, $60 \%$ males and $38 \%$ females) of respondents selected item (c).

Regarding statement25, "It is easier to speak than understand a foreign language." $(23 \%)$ of male and (18\%) of female respondents agreed with the item. So totally $(20 \%)$ of respondents had a positive idea about this item. However, (21\% totally, $27 \%$ males and $18 \%$ females) of respondents were neither agreed nor disagreed with this idea.

According statement34, "It is easier to read and write English than to speak and understand it." (33\%) of male and $(26 \%)$ of female respondents agreed with the item. So totally $(29 \%)$ of respondents had a positive idea about this item. However, (16\% totally, $17 \%$ males and $16 \%$ females) of respondents were neither agreed nor disagreed with this idea. Most students shared the same opinion about the difficulty of English language and the time required to learn it.

\section{T-test for Gender Differences}

A comparison analysis of the gained result between males and females

Statistical hypothesis:

$$
\left\{\begin{array}{l}
H_{0}: \mu_{1}=\mu_{2} \\
H_{1}: \mu_{1} \neq \mu_{2}
\end{array}\right.
$$

Table 6. A comparison analysis of the gained result between males and females

\begin{tabular}{cccccccc}
\hline Hypothesis & Gender & Population & Mean & SD & $\begin{array}{c}\text { Calculated } \\
\text { T }\end{array}$ & Pv & Test result \\
& & & & & 0.107 & 0915 & Ho \\
\hline Writing ab & Male & 30 & 67.87 & 13.06 & & & \\
ility Score & Female & 50 & 67.6 & 9.17 & & 0.3 & Ho \\
All & Male & 30 & 3.33 & 0.39 & 1.042 & & \\
categories & Female & 50 & 3.21 & 0.50 & & & \\
\hline \hline
\end{tabular}

Page $\mid 170$ 
To be able to make a comparison between experimental group's BALLI's scores and their writing ability and also between control group's BALLI's scores and their writing ability, both the experimental and the control group were administered a post-test at the end of the semester.

The independent-samples t-test analysis revealed that there was no significant difference between the mean scores of the participants in the two groups. According to the calculated p-value which is more than 0.05 we conclude that the Ho is verified and the research hypothesis is rejected. It was shown that in spite of the fact that males and females reported holding various opinions about language learning, but it is not significant. Actually according to our research there is no significant effect of gender differences' learning beliefs on their writing ability. The majority of students holding positive and realistic idea about language learning beliefs either male or female made high range of scores of writing. On the other hand students holding negative and unrealistic idea about language learning beliefs either male or female made low range of scores of writing.

\section{Hypothesis Analysis (Discussion)}

The following two research questions are addressed in the present research:

1. How specifically are foreign language learners' beliefs about language learning related to their writing ability?

2. Is there any significant effect of gender differences' learning beliefs on their writing ability?

The following hypotheses are drawn:

1. There is a relationship between Iranian EFL learners' beliefs and their writing ability.

2. There is not significant effect of gender differences' Learning beliefs on their writing ability.

A total of 80 students were homogeneously selected based on the OPT score among upper-intermediate participants in some English language institutes in Amol, Babol, and Babolsar, Mazandaran, Iran. The participants were asked to complete Horwitz's BALLI questionnaire (1987) to sort them out in control group (negative beliefs) and experimental group (positive beliefs). The BALLI is a quantitative self-report questionnaire that investigates 34 different learner beliefs on a likert-scale. A post writing ability test (a free composition) was administered at the end of the semester. The given statements and scores were analyzed by Statistical Package for Social Sciences (SPSS) to assess the results. Furthermore Distribution of $t$ was conducted for gender differences. The findings reveal that learners have different beliefs toward learning English as a foreign language. The findings show a significant relationship between Iranian EFL learners' beliefs about foreign language learning and their writing ability. Participants who have more positive and realistic beliefs about foreign language learning make good to excellent scores in their writing ability test and the students, who have negative and unrealistic beliefs about foreign language learning mostly make bad to fair in their writing ability test. The findings also reveal that there is no significant effect of gender differences' learning beliefs on their writing ability. The findings of the present study may suggest teachers to foster positive and realistic beliefs that lead to effective learning of writing ability and minimize negative beliefs that inhibit learning.

According to the calculated $\mathrm{p}$-value which is more than 0.05 we conclude that the Ho is verified and the research hypothesis is rejected.

Teachers can draw on findings to facilitate more effective instructional planning and implementation (greater consideration for choice of teaching methods and materials, lesson content and sequence). Moreover, the knowledge of student beliefs will make it possible for teachers to create a mode of instruction in which students' needs and goals are satisfied.

\section{Gender Differences}

The present study also attempts to find the answer of the following research question:

"Is there any significant effect of gender differences' learning beliefs on their writing ability?"

It was shown that in spite of the fact that males and females reported holding various opinions about language learning, but it is not significant. Actually according to our research there is no significant effect of gender differences' learning beliefs on their writing ability. The majority of students holding positive and realistic idea about language learning beliefs either male or female made high range of scores of writing. On the other hand students holding negative and unrealistic idea about language learning beliefs either male or female made low range of scores of writing. So the following hypothesis is rejected: there is no significant effect of gender differences' Learning beliefs on their writing ability. 


\section{Pedagogical Implications}

The findings of this study can have several important pedagogical implications for both learning and teaching. The analysis of the BALLI items revealed that different students had different beliefs towards learning English as a foreign language. Iranian students in this study showed their great eagerness to learn this internationally accepted language very well, and this is surely a very helpful belief that can facilitate language learning. According to the present research there are some harmful beliefs that they hold such as placing an emphasis on grammar and translation, and believing that less than two years for learning English is enough. In this case, the students are faced with unrealistic and negative beliefs clashing with the reality of language learning and consequently frustrations and disappointments might emerge. In such cases, it is the role of the teacher to "confront erroneous beliefs with new information', (Horwitz, 1987, p. 126).

Not only in this study, but also in other previously conducted studies the unrealistic and negative beliefs are seen. Sometimes the source of such wrong beliefs goes back to what is known as culture or background. Therefore, culture and background of the students should also be taken into account by teachers. It seems that there is a need for teachers to devote sessions to talk with students about the real and helpful beliefs about language learning. This will help both students to become familiar with correct and realistic beliefs and teachers to get most from their classes.

\section{Suggestion for Further Research}

The findings of this study suggest that the following areas need to be investigated in the future:

1. The other domain of language (vocabulary, grammar, and listening) skill can be investigated through the self-report questionnaire of the BALLI.

2. Iranian EFL learners' beliefs about language learning, focusing their relationship with the background variables (such as sex, age, language proficiency,) need to be investigated.

\section{References}

Bernat, E. and Gvozdenko, I. (2005). Beliefs about language learning: current knowledge, pedagogical implications, and new research direction. TESL-EJ, 9(1), 1-13.

Dehghan Harati, R. (2011). Learners' beliefs, teachers' beliefs: Are they different? The Iranian EFL journal Oct., 2011, 7(5).

Ghobadi, S. and Khodadady, (2011). Investigating university students' beliefs about language learning, $R E L C$ Journal, 42, 291- 304

Hughes, A. (2003). Testing for language teachers, Cambridge, third edition.

Horwitz, E. K. (1987). Surveying student beliefs about language learning, Prentice Hall, London, 119-129.

Horwitz, E. K. (1988). The Beliefs about language learning of beginning university, foreign language students, Modern Language Journal, 10, 283-294.

Horwitz, E. K. (1999). Cultural and situational influences on foreign language learners' beliefs about language learning: a review of BALLI studies. System, 2 (3).

McDonough, (1995). Strategy and Skill in Learning a Foreign Language, London, Edward Arnold

Nunan, D. (2001). Second language teaching and learning, Heinle and Heinle publication.Pp.271-299

Oxford, R. L. (1990a). Language learning strategies: What every teacher should know. Boston: Heinle \& Heinle.

Richardson, V. (1996). The Role of attitudes and beliefs in learning to teach, Hand book of Research on Teacher Education, New York, Macmillan

Schommer, M. (1990). Effects of beliefs about the nature of knowledge on comprehension, Journal of Educational Psychology, 82(3), 498-504

Victori, M. and Lockhart, W. (1995). Enhancing meta-cognition in self-directed language learning. System 23, 223-234.

Zare-ee A. (2010). Association between university students' beliefs and their learning strategy use (ScienceDirect2010). 